\title{
Going international? Risk taking by cryptomarket drug vendors
}

DOI:

10.1016/j.drugpo.2016.06.003

\section{Document Version}

Accepted author manuscript

Link to publication record in Manchester Research Explorer

\section{Citation for published version (APA):}

Décary-Hétu, D., Paquet-Clouston, M., \& Aldridge, J. (2016). Going international? Risk taking by cryptomarket drug vendors. International Journal of Drug Policy, 35, 69-76. https://doi.org/10.1016/j.drugpo.2016.06.003

\section{Published in:}

International Journal of Drug Policy

\section{Citing this paper}

Please note that where the full-text provided on Manchester Research Explorer is the Author Accepted Manuscript or Proof version this may differ from the final Published version. If citing, it is advised that you check and use the publisher's definitive version.

\section{General rights}

Copyright and moral rights for the publications made accessible in the Research Explorer are retained by the authors and/or other copyright owners and it is a condition of accessing publications that users recognise and abide by the legal requirements associated with these rights.

\section{Takedown policy}

If you believe that this document breaches copyright please refer to the University of Manchester's Takedown Procedures [http://man.ac.uk/04Y6Bo] or contact uml.scholarlycommunications@manchester.ac.uk providing relevant details, so we can investigate your claim.

\section{OPEN ACCESS}




\section{Accepted Manuscript}

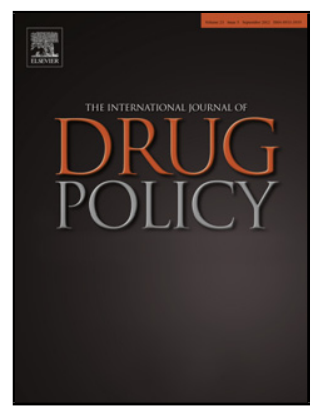

Title: Going International? Risk Taking by Cryptomarket Drug Vendors

Author: David Décary-Hétu Masarah Paquet-Clouston Judith Aldridge

PII: S0955-3959(16)30172-4

DOI: http://dx.doi.org/doi:10.1016/j.drugpo.2016.06.003

Reference: DRUPOL 1800

To appear in: International Journal of Drug Policy

Received date: 10-8-2015

Revised date: 25-5-2016

Accepted date: 1-6-2016

Please cite this article as: Décary-Hétu, D., Paquet-Clouston, M., and Aldridge, J.,Going International? Risk Taking by Cryptomarket Drug Vendors, International Journal of Drug Policy (2016), http://dx.doi.org/10.1016/j.drugpo.2016.06.003

This is a PDF file of an unedited manuscript that has been accepted for publication. As a service to our customers we are providing this early version of the manuscript. The manuscript will undergo copyediting, typesetting, and review of the resulting proof before it is published in its final form. Please note that during the production process errors may be discovered which could affect the content, and all legal disclaimers that apply to the journal pertain. 


\section{Title}

Going International? Risk Taking by Cryptomarket Drug Vendors

\section{Author names and affiliations}

David Décary-Hétu ${ }^{a, b}$ Masarah Paquet-Clouston ${ }^{b}$ \& Judith Aldridge ${ }^{c}$

${ }^{a}$ School of Criminology, University of Montreal, Montreal, H3C 3J7

${ }^{\mathrm{b}}$ International Centre for Comparative Criminology (ICCC)

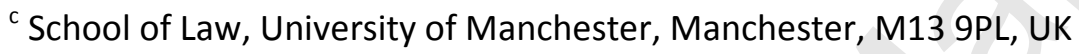

Corresponding author: David Décary-Hétu (david.decary-hetu@umontreal.ca) 


\section{Title}

Going International? Risk Taking by Cryptomarket Drug Vendors

\section{Abstract}

\section{Background}

Since 2011, we have witnessed the rise of 'dark net' drug marketplaces known as cryptomarkets. Cryptomarkets operate on the same model as eBay as they provide a platform where authorized vendors can set up a virtual shop and place listings. Building on a growing body of literature that seeks to understand cryptomarket participants, this paper seeks to explain the decision of cryptomarket vendors to take on risk.

\section{Methods}

We collected data on Silk Road 1 (SR1), the first cryptomarket launched in 2011. We propose a multilevel model that takes into account the characteristics of listings, vendors and their environment to explain the decision of vendors to take on risk.

\section{Results}

Our results demonstrate that all levels in the model significantly explain the decision to take on risk. Risk taking, operationalized as a willingness to ship drugs across international borders, was associated with the weights of drug packages mailed, the vendors' reputations and numbers of listings, the country-level perceived effectiveness of law enforcement according to experts, and the opportunities available to vendors as measured by the wealth and the drug expenditures of potential customers.

\section{Conclusions}

Our results support some previous research findings on the factors explaining risk taking. We extend existing literature by emphasizing the relevance of the environment of drug dealers to predict risk taking.

\section{Key words}

Cryptomarkets; dark net drug markets; illegal drug markets; risk taking 


\section{Going International? Risk Taking by Cryptomarket Drug Vendors}

\section{Introduction}

Online illicit markets are virtual meeting places where illicit goods and services can be bought and sold (Holt \& Lampke, 2010). These markets have traditionally been hosted in chat rooms and discussions forums and have mostly attracted financial fraudsters and computer hackers. Recently, a second generation of online illicit marketplaces started to gain traction (Martin, 2014a). Known as cryptomarkets, they differentiate themselves from first generation online illicit markets by their focus on the sale of drugs (Aldridge \& Décary-Hétu, 2014; Christin, 2013) and the operational security they provide.

Cryptomarkets have garnered considerable attention from researchers recently (see Christin, 2013; Barratt et al., 2014; Martin, 2014a, 2014b). Visually, they are very similar to online marketplaces like eBay with their list of products and their individual pages for listings and vendor profiles. On the business end, cryptomarkets operate on the same model as eBay; they provide a platform where authorized vendors can set up a virtual shop and place listings. Market administrators establish the basic rules under which all market participants must operate (Christin, 2013). Vendors and customers come from all over the world though most come from Western countries such as the United States, the United Kingdom, the Netherlands and Canada (Christin, 2013). The 1st cryptomarket, Silk Road (SR1), was launched in February 2011. Although it was eventually taken down by law enforcement late in 2013, SR1 appeared to provide a high level of security and anonymity to its participants. Indeed, of the hundreds of thousands of participants, only a very small fraction was reported being arrested following the take down of the cryptomarket (Branwen, 2015).

Building on a growing body of literature characterizing cryptomarket participants (see Christin, 2013; Barratt et al., 2014; Martin, 2014a, 2014b), this paper seeks to explain the decision of cryptomarket vendors to take on risks. Risk has been modeled as a driving force for offenders in general and drug dealers in particular. Research attention has so far focused on the personal characteristics that push individuals towards risk taking and offending. The research reported in this paper extends beyond these individual-level factors in explaining risk taking to include environmental factors, building in part on Rhodes' (2002) past research. Understanding how and when drug dealers take on risks is important because it helps us to predict how cryptomarkets will impact global drug sales. Indeed, cryptomarkets provide a new distribution channel for drug dealers; if and when this distribution channel replaces parts of the traditional drug smuggling and drug dealing will depend in part on the risk-taking behavior of cryptomarket participants.

This paper begins with a definition of the general concept of risk. Section 1 and 2 present explanations for risk taking and the types of risks that drug dealers face. Section 3 presents the rationale for studying risk in the context of cryptomarkets. Section 4 introduces our dataset, a copy of Silk Road 1 (SR1), the first cryptomarket to be launched in 2011. It also presents our multilevel model which predicts the willingness of vendors to ship their drugs internationally, our proxy for risk taking. Section 5 and 6 
highlight our contribution to the literature on risk taking as well as the policy implications of our findings.

\section{On the willingness to take on risks}

In its most generic form, risk can be defined as "a measure of exposure to danger, of the likelihood and the extent of loss" (Garland, 2003: p.2) and it abounds in uncertain situations where outcomes are difficult to predict. While offenders vary in their willingness to take on risks, researchers have found that they score higher on the risk-taking scale (van Duyne, 1999; Lane \& Cherek, 2000; Smith, 2009; Murat et al., 2014) though some have failed to detect a significant difference between offenders and nonoffenders (Krueger et al., 1994). The propensity for risk taking is correlated with the level of criminal activity (Becker, 1974; Ehrlich, 1974; de Mesquita \& Cohen 1995; McCarthy, 2002).

There are competing explanations as to why offenders, whose activities involve the potential for harm, are willing - or indeed not willing - to take on risks. The most common explanations center on psychological factors. These include psychopathy (Swoger et al., 2010), low self-control (Gottfredson \& Hirschi, 1990) and the ability to delay gratification and temperance (Little, 2006; Romer et al, 2010). These last two factors relate to a cost/benefit analysis by offenders who evaluate the costs of taking on risks versus the potential rewards of taking on those risks. Psychological factors also extend to offenders who perceive themselves as invincible; some have such faith in their 'unique' abilities that they believe themselves able to take on more risks than others (McCarthy \& Hagan, 2005). Another common explanation of risk taking centers on the personal and social capital of offenders. More experienced, older offenders tend to take on fewer risks (Gardner \& Steinberg, 2005). Those with few opportunities and little access to legitimate and illegitimate opportunities and resources are more willing to take on risky behaviours (Black \& Ricardo, 1994; Gardner \& Steinberg, 2005). Taking on risks may, finally, be motivated by situational factors such as being intoxicated (Lane et al., 2004) and peer pressure (Hensley, 1977; Gardner \& Steinberg, 2005).

\section{The risks of dealing drugs}

Past research on the risks of dealing drugs has mainly focused on the risk of arrest (Reuter \& Kleinman, 1986; Reuter \& Haaga, 1989; MacCoun \& Reuter, 1992; May \& Hough, 2004) as drug dealers are prime targets for law enforcement. We suggest that for drug dealers, the nature of risk can usefully be categorized into four domains: the risk of arrest, the risk of violence, the risk to profits and the risk to reputation.

The risk of arrest varies depending on the drug dealers' roles and positions (Reuter \& Haaga, 1989) and their proximity to both money and drugs (Skolnick et al., 1990). Researchers have found that the risk of arrest is much higher for drug dealers than for drug users (Reuter \& Kleinman, 1986; Bouchard \& Tremblay, 2005) and, in comparison, to many other types of offenders (Skolnick et al., 1990; Bouchard \& Tremblay, 2005). The risk of arrest varies by the type of drug sold and varies depending on the setting and the time period (e.g. Reuter \& Kleinman, 1986; Reuter \& Haaga, 1989; Bouchard \& Tremblay, 2005). An important predictor of the risk of arrest is the level of law enforcement (Reuter \& Kleinman, 1986) with increased enforcement leading to higher risk of arrest. 
Law enforcement also poses a risk of violence to drug dealers. Case study research has shown that drug dealers may be victims of violence at the hands of law enforcement agents either during an arrest or during their daily interactions with them (Werb et al., 2008). Competitors (Reuter \& Kleinman, 1986; Reuter \& Haaga, 1989; Skolnick et al., 1990) and customers (May \& Hough, 2004; Fitzgerald, 2009; Fairlie, 2014; Topalli et al., 2015) may also employ violence or threats to steal money and drugs from dealers.

These victimizations are one of the factors that may pose a risk to profits. This risk may be incurred in a number of ways, including the loss of drugs or money following an arrest (Caulkins et al., 1999; Fairlie, 2014) or theft by competitors (Reuter \& Kleinman, 1986; Reuter \& Haaga, 1989; Skolnick et al., 1990; Caulkins et al., 1999), customers (Caulkins et al., 1999; Fairlie, 2014) and employees (Caulkins et al., 1999). A drug dealer's profits may also be affected by customers who default on payments (Reuter \& Haaga, 1989) or when the drugs they source as stock for resale are not as advertised (Caulkins et al., 1999).

To maintain profits, drug dealers need to minimize their risk to reputation. Reputation is an important capital for drug dealers who can build a reputation based on their use of violence, their fairness, the quality of their drugs or their customer service. Competitors and customers are much less likely to steal or otherwise threaten dealers who have a reputation for violence and retaliation (Jacobs et al., 2000; Anderson, 2000; Topalli et al., 2015). A reputation for fairness is also important for building long-term associations with business partners, employees and customers, thereby reducing the odds that these individuals will become informants (Reuter \& Kleinman, 1986; Denton \& O'Malley, 1999). Rumors can affect drug dealers' reputations and expose them to violence, to arrest and to lost opportunities; drug dealers must therefore build and care for their reputation.

When facing any of these four risks, successful drug dealers will adapt. Adaptations identified by researchers connected to offline markets include: sourcing of drugs locally rather than via importation; adopting new technologies like pagers and cellphones (Adler, 1993; Reuter \& Kleinman, 1986; Caulkins et al., 1999; May \& Hough, 2004; Bouchard, 2007); selling only to trusted customers and; choosing safer locations to conduct sales (Johnson \& Natarajan, 1995; Cross, 2000; Moloney et al., 2015). For drug dealers, the "risks associated with drug sales are not simply passively accepted but are actively navigated" (Moloney et al., 2015: p.4). Drug dealers should be considered active agents (Johnson \& Natarajan, 1995) who decide "what to sell, where to sell and whom to sell to" (Moloney et al., 2015: p.4; see also Bouchard \& Tremblay, 2005).

\section{Taking on risks and the shift to cryptomarkets}

The decision to discriminate to whom drug dealers sell is linked to a shift from risky open drug markets to closed drug markets (May \& Hough, 2004) and the adoption of pagers and cellphones. More recently, another shift, motivated this time by the adaptation of encrypted communications, has pushed drug dealers away from closed drug markets towards 'anonymous open' markets (Aldridge \& Décary-Hétu, forthcoming) hosted on the Internet. Researchers have long established that prescription drugs have been made available illegally online (Yang et al., 2001; Littlejohn et al., 2005; Levchenko et al., 2011; Leontiadis et al., 2013). It has only been since 2011, however, with the launch of Silk Road, that we have 
witnessed the large scale supply of a wide range of illegal drugs sold online on via 'dark net' drug marketplaces known as cryptomarkets that offer a high level of anonymity to their users.

Dealing drugs on cryptomarkets rather than in traditional offline drug markets may change the risks to which drug dealers are exposed. Cryptomarkets may first change the risk of detection and arrest by protecting a vendor's identity. At least at this point in time, drug law enforcement officials will have relatively limited experience investigating online drug sales and financial transaction in cryptocurrencies. Law enforcement is therefore likely to be less effective when targeting cryptomarket vendors. Operating online also changes the risk of violence as it eliminates the need for face-to-face transactions. Using violence to resolve conflicts or steal can therefore not be an option. The risk to profits is still present in cryptomarkets as vendors sourcing their stock online could purchase weaker than advertised drugs or have some of their packages seized in transit. The use of escrow and the inability for customers to purchase on credit may, however, work to limit the risks to profits. Anecdotal evidence also suggests that the risks of seizures are low (Branwen, 2015) though the data to compare offline and online risk of seizures are lacking at the moment. Finally, cryptomarkets impact the risk to reputation through the use of online automated feedback systems which record the interactions between vendors and buyers. Vendors are therefore able not only to build a certain reputation but to broadcast this reputation, without interference, to all of the cryptomarket participants and use it to foster their resources and opportunities.

Cryptomarkets provide a new distribution channel for which the costs and benefits associated with risk taking are still very much unknown. This raises many questions about the profile of individuals who are willing to take on the risks of dealing drugs on cryptomarkets and the context in which they are likely to do so. Would these individuals be limited only to the most daring risk takers? Or would these individuals include some who were unwilling to take on the risks of dealing drugs before and who are now drawn in to dealing because of the features of cryptomarkets? This paper provides the first empirical insights into the concept of risk taking in the context of cryptomarkets and seeks to explain the decision of cryptomarket vendors to take on risk. As cryptomarket vendors are a very difficult population to reach, this study will seek to understand risk taking by using digital trace estimates of risk taking activity in online sales rather than self-reported risk taking. To do so, we propose a multilevel model that takes into account the characteristics of the drugs being sold, the characteristics of the vendors and the characteristics of the environment in which the vendors operate. This model measures the risk taking of vendors by predicting the factors that lead to a specific risky behavior, shipping drugs internationally (across national borders) rather than only domestically.

Shipping internationally can be considered as a risky activity because it increases the risks of detection when drugs move across international borders (Volery, 2015). The risks of shipping internationally are highlighted by a systematic review of press articles that detail the arrests of cryptomarket participants. Branwen (2015) found that as of May 2015, 62\% (70/113) of cryptomarket vendors that had been arrested were arrested in connection to international shipments. Because of the risks associated with shipping internationally, only a subset of cryptomarket vendors are willing to do so. These individuals could be considered as risk takers (Neumann \& Morgenstern, 1944) and provide us with an opportunity to understand how vendors take on risk in the particular context of online drug dealing. 
Understanding how and when drug dealers take on risks will help us to predict how cryptomarkets will impact global drug sales. As cryptomarkets provide a new distribution channel for drug dealers, the risks associated with their use is still very much unknown. Many dealers may therefore be reluctant to take on the gamble of dealing drugs online. Understanding the conditions under which drug dealers are willing to take on risk online will allow us to better predict the likely adoption rate of cryptomarkets and model the benefits and harms associated with this new distribution channel.

\section{Data and methods}

\section{Data collection}

We collected our data from the first major cryptomarket, SR1, from September $13^{\text {th }}$ to September $15^{\text {th }}$ 2013. To do so, the DATACRYPTO (Décary-Hétu \& Aldridge, 2015a) tool we developed logged in to the cryptomarket and downloaded a copy of all of the listings, vendor profiles and customers' feedback. The SR1 dataset, once cleaned, included 7,487 listings from 923 vendors operating in 35 countries, down from the initially collected 11,904 listings (see Appendix A for more details on the sampling strategy). Some might perceive the selection of the first cryptomarket as a limitation. We provide here, however, benchmark data to which data collected in connection to later marketplaces can be compared particularly relevant in the present context, where risk has risen with more and more arrests taking place. These benchmark data are particularly useful, having been collected at a time when vendors felt relatively impervious and could therefore act with a relative impunity.

While the DATACRUPTO tool provided us with an extensive picture of cryptomarket activities back in 2013, we also gathered further information on the vendors' environment using open sources. The total national expenditure (in millions \$USD) on illicit drugs in each of the vendors' country is based on the United Nations Office on Drugs and Crime (UNODC) World Drugs Report (2005). While dated, this source of data is, to the best of our knowledge, the most recent available for all of the countries in our sample; there are no indications as to why newer figures were not made available in more recent versions of the report. As the report only provides data per capita expenditure aggregated the regional and continent level, the per capita expenditure on drugs from the region or continent was multiplied by the number of inhabitants in each country in 2013 (World Bank, 2015). Again, while not perfect, this measure is the most up-to-date information available on drug expenditures that covers all of the countries from which SR1 vendors operated. The gross domestic product per capita (GDP), a measure of the wealth of individuals in a country, comes from the World Bank (2013). The perceived effectiveness of law enforcement in each country of operation was measured by the 'Factor 8 ' of the 'rule of Law Index' in the survey from the World Justice Project (2013), a project launched in 2006 by the president of the American Bar Association (World Justice Project, 2015). The survey asks relevant experts about their perception of the efficiency and integrity of the criminal justice system in their own countries, taking into account domestic corruption. Finally, we also collected qualitative data from a cryptomarket forum on relevant shipping-related discussions. We do not present these data in the results, but use these to reflect on our analysis in the discussion section of the paper. We paraphrased our selections from these forums and removed any identifying information, to protect the anonymity of participants (Décary-Hétu \& Aldridge, 2015b). 


\section{The multilevel model}

The dependent variable is a dichotomous indicator of the willingness of the vendors to take on risks as measured by their willingness to ship internationally (1) or domestically (0) in each of their listings. Listings willing to ship to any country besides the one from which the associated vendor was located were considered as willing to ship internationally.

The listing level includes three variables: weight, competitive advantage and drug types. The weight was extracted from the title of each listing. To weigh the drugs sold as pills, we enlisted the help of a pharmacist who weighed different concentrations of nine types of prescription pills (Xanax, Viagra, Valium, Oxycodone, Cialis, Clonazepam, Modafinil, Lorazepam and Levitra) that represented 39\% of all prescription pills in our population. The weight per pill varied from 0.05 to 0.61 grams with an average of 0.19 grams (S.D. $=0.14 ; C V=0.71$ ). Given the limited variance in weight, the number of pills in each listing was multiplied by the average weight. Drugs that could not be weighed in grams were removed from the sample. Vendors may be willing to take on more risk with smaller weights as lighter packages may be more difficult to detect for law enforcement (Volery, 2015) and may incur fewer risks to profits if intercepted. Alternatively, vendors may only be willing to take on risk if they stand to earn more profits through large shipments. The competitive advantage measures the ratio between the listing's price per gram and the price per gram of listings for the same drug type from vendors based in other countries. We expect here that the risk of shipping internationally should be compensated by the profits that can be made at the international level; vendors with a competitive advantage over others should therefore take on more risks (Reuter \& Haaga, 1989). Finally, the drug types were added as control variables and were coded as mutually exclusive dummy variables with tobacco as the comparison category. SR1 separated listings in ten categories (cannabis, dissociative, ecstasy, opioid, prescription, precursor, psychedelic, stimulant, tobacco and 'other' remaining drugs) and this classification was checked manually to confirm the validity of the data. Drug types were included in the multilevel model but are not presented in Table 2 to improve its clarity as the results are only indicative of whether certain drug types predict risk taking more or less than the reference category.

The vendor level includes four variables: vendor rating, estimated yearly revenues, product diversity and number of listings. SR1 provided for each vendor an aggregated vendor rating based on the customers' feedback. As $71 \%$ of vendors had a perfect $5 / 5$ rating, the variable was recoded in two mutually exclusive categories, the vendors with a perfect score (1) and the other vendors (0). We expect the vendors with a less than perfect rating to take on more risk. Past research (Black \& Ricardo, 1994; Gardner \& Steinberg, 2005) has found that offenders with fewer opportunities and resources are more willing to take on risks and vendors may not have much opportunities when competing domestically against vendors with perfect rating scores. While feedback was not mandatory on SR1, it was strongly encouraged by the administrators, making feedbacks a commonly used proxy for the number of sales on cryptomarkets (Soska \& Christin, 2015; Aldridge \& Décary-Hétu, 2014). Estimated yearly revenues were thus calculated by multiplying the number of feedbacks for each listing in the 30-day period before the collection date by the price of the listing. Revenues were then multiplied by 12 to obtain yearly estimates and aggregated at the vendor level. Contrary to Soska \& Christin (2015) who opted to remove from their sample all of the listings priced over $\$ 50,000$ USD as well as those too far from the mean, we 
decided to manually assess all of the listings over $\$ 10,000$ USD and to remove only the listings that were clearly marked as having a 'holding price'. The 'holding price' indication was used by dealers who wanted to keep their listing up but did not want anyone making a purchase while they were out of stock.We also expect vendors with smaller revenues to take on more risk in order to expand their illegitimate opportunities. Finally, the product diversity is the number of drug categories a vendor is offering listings in. It is controlled by the number of listings.

The environment level includes four variables: the national drug expenditure on illicit drugs, the GDP per capita, the domestic competition per 1,000,000 inhabitants and the perceived effectiveness of law enforcement. The national drug expenditure and the GDP per capita provide an estimate of the potential customer pool in each country. We expect vendors to be willing to take on more risk should the opportunities in their own country be limited. The domestic competition per 1,000,000 inhabitants is a measure of the number of vendors selling the same drug category in the same country. For the same reasons, we also expect the vendors operating in the countries with the highest level of competition to be willing to take on more risk. Finally, the perceived effectiveness of law enforcement will control for the risk of arrest of vendors. Vendors in countries with a higher perceived level of effectiveness of law enforcement may be less willing to take on more risks.

Analysis

The purpose of multilevel models is to predict a dependent variable based on explanatory variables associated with different levels (Scott et al., 2013). Multilevel models help to avoid violating the assumption of independence of errors since they control for the group effect within a sample. Our multilevel model estimates the relationship between listings shipping internationally and independent variables measured at three levels: listings that are nested into vendors, and vendors that are nested into environment (or countries). As the dependent variable is dichotomous, we selected a nonlinear model and a random intercept three-level Hierarchical Generalized Linear Model (HGLM). The HLM7 software was used to run the analysis (Raudenbush et al., 2004). All variables with a skewed distribution were logged.

\section{Results}

The main objective of this paper is to explain the decision of cryptomarket vendors to take on risk. The descriptive statistics are first presented in Table 1. Since some variables are highly skewed, the median and the interquartile range (IQR) are presented. In line with past research (Murat et al., 2014; Smith, 2009; van Duyne, 1999; Lane \& Cherek, 2000; Weinfurt \& Bush, 1995), they show that many cryptomarket vendors could be considered risk takers, as those willing to ship internationally hold $69 \%$ of all listings and about $61 \%$ of revenues. This finding is important as it demonstrates how common the form of risk taking we have chosen - the willingness to ship internationally - is. While still indicative of the features of risk takers, our results therefore probably do not only apply to the most extreme risk takers but instead to a larger portion of the vendor community who has a propensity for risk taking.

\section{[ INSERT TABLE 1 ABOUT HERE ]}


Results from the multilevel analysis found that listings shipping internationally varied depending on the characteristics of vendors $\left(\chi^{2}=2889.37, \mathrm{DDL}=884\right)$ and the environment in which these vendors operated $\left(\chi^{2}=162.07, \mathrm{DDL}=30\right)$. These findings demonstrate that the use of a multilevel model is appropriate and desired for the data structure. Results of the model with fixed predictors are presented in Table 2.

\section{[ INSERT TABLE 2 ABOUT HERE ]}

At the listing level, smaller weights are associated with listings shipping internationally (Coefficient = 0.315). No association was found between listings shipping internationally and their competitive advantage. At the vendor level, vendors with less than perfect ratings were more likely to be associated with listings shipping internationally (Coefficient $=-0.314$ ). Also, listings shipping internationally were positively associated with vendors offering more products overall (Coefficient $=0.389$ ). At the environment level, a significant negative relationship was found between listings shipping internationally and drug expenditure (Coefficient $=-2.115$ ) of the vendors' country. Listings shipping internationally were also negatively associated with the GDP per capita (Coefficient= -3.358 ) and the perceived efficiency of law enforcement (Coefficient= -16.712 ) of the vendor's country. No association was found for domestic competition.

\section{Discussion}

Our analysis was predicated on the assumption that offering international shipments is indicative of the willingness of cryptomarket vendors to take on risk. Forum discussions confirmed that the risk of loss was believed to be increased for international shipments among cryptomarket participants: "packages have a higher chance of being inspected internationally, and therefore higher probability of seizure" and "the worst thing about international sales is that buyers can more easily claim they did not receive the package". Cryptomarkets have been described as international markets where illegal drugs can be shipped to and from anywhere in the world (Christin, 2013; Martin, 2014a). Vendors willing to ship internationally generated about $61 \%$ of estimated revenues on SR 1 from $69 \%$ of all listings. This suggests that vendors willing to take on risk by shipping internationally - quite apart from how often they actually did - were important to the operations of SR1. This class of vendors spawns above and beyond the smaller number of extreme risk takers and includes a larger number of vendors who vary in their risk taking propensity. Further research should build on our model and seek to apply it to the subset of vendors who score the highest on a risk-taking scale (such as Blais \& Weber's (2006) DOSPERT scale).

In our sample, the environment level variables played a key role in explaining risk taking by cryptomarket vendors; the setting in which vendors operate has an important impact on their decision to offer international shipping. The environment has been known for over a decade to impact harm reduction efforts and increase drug users' risks (Rhodes, 2002). Cutbacks in social programs, shortages of clean needles and syringes and an increase in the use of cocaine in Vancouver in the late 1990s created the perfect conditions for an HIV outbreak among injectable drug users (O'Shaughnessy, Montaner, Strathdee \& Schechter, 1998). This environment forced drug users to adopt riskier behaviors to sustain their drug habit. Our results fall in line with such findings and suggests that the environment shapes the decision of drug dealers to offer international shipping. 
This study extends the literature on risk taking on drug dealing which has focused on psychological factors (Swoger et al., 2010; Little, 2006; Romer et al, 2010), situational factors (Hensley, 1977; Gardner \& Steinberg, 2005) as well as personal and social capital (Black \& Ricardo, 1994; Gardner \& Steinberg, 2005). Vendors in countries with a lower national drug expenditure and a lower GDP per capita were significantly more likely to take on more risk by offering international shipping. Our finding that cryptomarket vendors in poorer countries and those with less expenditure on illegal drugs suggests that these vendors may lack a sufficient market of 'good' customers domestically, pressuring them to take the risk of accessing the market of international customers made available through cryptomarkets. This is an important change as drug dealers in physical markets (with the exception of importers) are limited to customers in their general geographical vicinity (Reuter, 1983). Cryptomarkets can therefore increase the opportunities of certain drug dealers, though at the possible cost of additional risks. These findings should be considered with care however as the drug expenditure measures, though the only ones available for all of the countries in our sample, date back from 2005.

Drug dealers who lack access to certain resources or opportunities have been found to be more willing to take on risk (Black \& Ricardo, 1994; Gardner \& Steinberg, 2005). Reputation is a resource to which some drug dealers may have limited access to. We operationalized reputation using customer feedback ratings, comparing those with perfect ratings associated with their vendor profiles to those with less than perfect ratings. The latter may perceive themselves to be at a relative competitive disadvantage and, as a result, may have been willing to offer international shipping to mitigate the negative impact of their less than perfect customer feedback scores. The causal direction of this explanation may operate in reverse: selling internationally may negatively affect a vendor's rating because of a higher number of intercepted or delayed shipments. Research suggests that risk takers may perceive benefits in a gamble (Becker, 1974; De Mesquita \& Cohen, 1995) especially when perceived costs are not prohibitive. Perfectly rated vendors, therefore, may conclude that the loss of vendor reputation is not worth the risk that international sales may entail. Forum discussions corroborated this interpretation: "You have to factor in the increased chance of international packages being seized, and accept the risk to yourself of the loss of funds"; "When sending to other countries, never send more than you can afford to lose".

At the listing level, smaller packages were more likely to be shipped internationally. This was expected as smaller packages were less likely to be inspected (Volery, 2015). The literature tells us that, even given the varying propensity to risk taking amongst individual drug sellers, these risks are actively managed and reduced (Johnson \& Natarajan, 1995; Moloney et al., 2015). Vendors may be willing to ship internationally if they believe that smaller packages would be less likely to be searched or confiscated by border officials, thus reducing the chance that a shipment would not reach a customer, with the risks of arrest, to profit and to reputation that ensue. It seems likely that shipments in smaller drugs quantities would be less easily identified using the strategies of border officials (dogs, visual inspections, X-rays, scanners) and thus selected for investigation as a result (U.S. Department of Homeland Security, 2014). Forum discussion confirmed that many vendors believed that smaller consignments were safer for international shipping: "Anything that will fit in a plain letter envelope is much more likely to make it through customs"; "If it fits in a bubble mailer and/or weighs less than 13 oz, you should be safer" and; "The trick to international shipping is making the package appear to 
contain nothing more than a few papers". Making low weight shipments may therefore be an adaptation technique for reducing the risks incurred through international sales.

The perceived effectiveness of law enforcement appears to impact the vendors' decision to offer international shipping. In the context of dark net drug sales, this finding makes sense. Indeed, even where an international shipment is successfully traced back to a vendor, ineffective law enforcement in a vendor's own jurisdiction may work to reduce the chances of successful prosecution. Moreover, as the majority of inspections are made when packages are leaving or entering a country (Volery, 2015), many vendors may have felt that an effective law enforcement would more likely intercept drug packages on their way out of the country, thereby increasing their risk of arrest. Our findings contradict those of Holt and colleagues, who found that that the scarcity of arrests in online illicit markets is seen as a sign of the low-level threat that law enforcement poses: "the greatest risks to buyers and sellers came from within the market rather than from external sources of social control" (Holt et al., 2015: p. 89). SR1's vendors clearly did perceive legal risks associated with their activities, and our findings confirm that those operating in jurisdictions with perceived inefficient law enforcement were more likely to take the risk of offering international shipping. Holt's research, however, focused on online markets for computer hacking and financial fraud, which may explain the difference in our results. Cryptomarket vendors deal in material goods, unlike those operating in online computer hacking markets, for example. Most vendors will also be engaging in offline drugs markets to source their supply, making the influence of local law enforcement more relevant to their operations.

Interestingly, the number of domestic competitors and the competitive advantage of listings were not associated with a willingness to ship internationally. This is surprising given that we expected both variables to increase risk taking in line with past research on drug dealers from Black \& Ricardo (1994) and Gardner \& Steinberg (2005). One possible explanation for this finding is that vendors may not have collated as detailed information about their competitors as we did. Doing so would have required browsing international competitor listings, and then calculating the average price of listings of domestic and international competitors. Vendors may have neglected to do so, or have done so insufficiently comprehensively to generate an accurate picture of the market. Alternatively (or additionally), in the growing market at SR1 was at the time (Aldridge \& Décary-Hétu, 2014), vendors may have perceived their income from domestic sales to be sufficient, such that there was no need to take this risk. The same may apply to domestic competition where vendors may not be aware of the number of competitors in their own country. They may wrongly feel that competition is limited when in fact it isn't.

We anticipated the possibility that vendors generating high revenues might be insufficiently motivated to ship abroad - a gamble not worth taking - but that vendors with lower revenues might be motivated as a result to take this risk. However, we did not find a significant relationship between a vendor's estimated yearly revenues and willingness to ship internationally. It is possible that our broad conceptualisation of risk taking did not allow for the relationship to fully express itself and further investigation should continue to explore the relationship between illicit earnings and risk taking. It is also possible that the profits in this growing market may have been sufficient without having to bear the risks associated with international shipping. These forum discussion comments by both domestic and international shippers are suggestive of this possibility: "Even if you only lose one package for every two 
you send, you'll still be rich in no time. There is so much profit to be made here" and the converse: "There are plenty of customers in [country] so there is no need to get international customers".

These findings contribute to the literature on risk first by conceptualizing the risks to drug dealers through arrests, violence, profits and reputation. These four themes are the most common in the literature but past research had failed so far to combine them into a single, unified conceptualization of risk. We demonstrate, moreover, that many cryptomarket vendors are willing to ship internationally. These vendors are likely to have a varying propensity for risk taking. Given the nature of our 'digital trace' methodology, we did not collect self-report data from vendors and therefore were unable to contribute to the research literature documenting psychological factors associated with risk taking. This paper focused on other factors associated with risk taking, namely the availability of opportunities and resources (Black \& Ricardo, 1994; Gardner \& Steinberg, 2005). In line with past research, we showed that the access to opportunities domestically (wealthier population, higher drug expenditures) reduces the willingness to offer international shipping. Our results suggest that cryptomarket vendors actively navigate the risks they face (Moloney et al., 2015; Johnson \& Natarajan, 1995) when deciding how best to evade detections through the shipment of smaller packages. We extend the literature by exploring the relationship between perceived effectiveness of law enforcement and a form of risk taking, offering international shipping. In the case of cryptomarkets, vendors appear to be aware of the level of law enforcement given that international shipping is less common in countries where perceived law enforcement is higher. While some offenders may have faith in their "unique" abilities as McCarthy \& Hagan (2005) point out, this is not the case of cryptomarket vendors who limit their risk taking in the face of perceived enforcement.

\section{Policy implications and limitations}

The main limitation of this paper comes from our inability to determine the true extent of international shipping transactions on SR1. The publicly available data from SR1 allowed us to determine whether the willingness to take on the risk of shipping internationally was present; but not the actual shipping of illicit drugs across borders. As this study focused on risk taking from the supply side, this issue is not as relevant, however, given that the behavior we monitored showed a willingness to take on risk, no matter if the risk was actually taken or not.

A large proportion of all SR1 cryptomarket vendors were willing to offer international shipping. This limited our ability to identify the vendors who were willing to take on the most risks. As such, our results should be interpreted as indicative of a propensity to take on a varying level of risk among cryptomarket vendors. Further research should build on our model to better identify risk takers in cryptomarkets and the variables that may influence risky behaviors.

Another limitation of this paper is the fact that its data come from SR1 and does not take into accounts the diversification of activities on new cryptomarkets. As more and more cryptomarkets emerge, the competition between the different markets has increased. Administrators of cryptomarkets are looking to increase the commissions they earn on each transaction made on their platforms and as such have tried to expand to other areas where illicit goods and services were offered on the Internet including intellectual property, financial fraud and hacking. SR1's main activities centered on the sale of drugs, so 
offenders involved in fraud and hacking would not necessarily be included in our study. Future research should look into the impact of the diversification of activities on cryptomarkets, particularly as it relates to risk. Indeed, vendors involved in different types of illicit goods and services may adopt different behavior depending on their activities. Research on risk taking should therefore make sure to classify vendors according to their online activities.

This paper opens the discussion on the international nature of cryptomarkets and the diffusion of drugs at the international level. We have seen that many vendors are willing to take on the risks of shipping internationally and we can expect this trend to continue moving forward with the expansion of cryptomarkets (Soska \& Christin, 2015). This places cryptomarkets firmly into the sight of regulators who are tasked with coordinating the enforcement of drug laws as well as the prevention of drug use. We suggest that monitoring systems be developed and adopted on a larger scale to continue to monitor the activities on cryptomarkets. These systems could be used as early warning systems to better prepare for changes in the evolution of drug use in the different countries and develop prevention programs that target the drugs being sold in these specific countries. We also suggest that risk taking be studied by these systems in order to understand the spread of illicit substances and the impact of enforcement actions on the activities of cryptomarket vendors and users. 


\section{References}

Adler, P. A. (1993). Wheeling And Dealing: An Ethnography Of An Upper-Level Drug Dealing And Smuggling Community. New York, USA: Columbia University Press.

Aldridge, J. \& D. Décary-Hétu. (2014). "Not an 'Ebay for Drugs': The Cryptomarket "Silk Road" as a Paradigm Shifting Criminal Innovation." Online: http://papers.ssrn.com/sol3/papers.cfm?abstract_id=2436643.

Aldridge, J. \& D. Décary-Hétu. (Accepted). " Hidden Wholesale: Characterizing the supply side of drug cryptomarkets." International Journal of Drug Policy.

Anderson, E. (2000). Code of the street: Decency, violence, and the moral life of the inner city. New York, USA: WW Norton \& Company.

Barratt, M. J. \& J. A. Ferris \& A. R. Winstock. (2014). "Use Of Silk Road, The Online Drug Marketplace, In The United Kingdom, Australia And The United States." Addiction. 109(5): 774-783.

Becker, G. S. (1974). "Crime and Punishment: An Economic Approach." IN Becker, G. S. \& W. M. Landes. (eds.). Essays In The Economics Of Crime And Punishment. Cambridge, USA: NBER.

Black, M. M. \& I. B. Ricardo. (1994). "Drug Use, Drug Trafficking, and Weapon Carrying among LowIncome African-American, Early Adolescent Boys." Pediatrics. 93(6): 1065-1072.

Blais, A. R. \& E.U. Weber. (2006). "A domain-specific risk-taking (DOSPERT) scale for adult populations." Judgment and Decision Making, 1(1): 33-47.

Bouchard, M. (2007). "A capture-recapture model to estimate the size of criminal populations and the risks of detection in a marijuana cultivation industry." Journal of quantitative criminology. 23(3): 221-241.

Bouchard, M. \& P. Tremblay. (2005). "Risks of arrest across drug markets: A capture-recapture analysis of "hidden" dealer and user populations." Journal of Drug Issues. 35(4): 733-754.

Branwen, G. (2015). "Tor Black-Market-Related Arrests." Online: http://www.gwern.net/Blackmarket\%20arrests.

Caulkins, J. P. \& B. Johnson \& A. Taylor \& L. Taylor. (1999). "What drug dealers tell us about their costs of doing business." Journal Of Drug Issues. 29(2): 323-340.

Christin, N. (2013). "Traveling The Silk Road: A Measurement Analysis Of A Large Anonymous Online Marketplace." Proceedings of the 22nd International Conference on World Wide Web. Geneva, Switzerland.

Cross, J. C. (2000). "Passing the buck: Risk avoidance and risk management in the illegal/informal drug trade." International journal of sociology and social policy. 20(9/10): 68-94.

De Mesquita, B. B. \& L. E. CohenE. (1995). "Self-Interest, Equity, And Crime Control: A Game-Theoretic Analysis Of Criminal Decision Making." Criminology. 33(4), 483-518.

Décary-Hétu, D. \& J. Aldridge. (2015a). "DATACRYPTO: A Dark Net Crawler And Scraper." Montreal, Quebec: University of Montreal.

Décary-Hétu, D. \& J. Aldridge. (2015b). "Sifting Through The Net: Monitoring Of Online Offenders By Researchers." The European Review Of Organised Crime. 2(2): 122-141.

Denton, B. \& P. O'Malley. (1999). "Gender, trust and business: women drug dealers in the illicit economy." British Journal of Criminology. 39(4): 513-530.

Ehrlich, I. (1974). "Participation in Illegitimate Activities: An Economic Analysis.". IN Becker, G. S. \& W. M. Landes. Essays in the Economics of Crime and Punishment. New York, USA: Columbia University Press.

Fairlie, R. W. (2002). "Drug Dealing and Legitimate Self-Employment." Journal of Labor Economics. 20(3): 538-537.

Fitzgerald, J. L. (2009). "Mapping the experience of drug dealing risk environments: An ethnographic case study." International Journal of Drug Policy. 20(3): 261-269. 
Forlani, D. \& J. W. Mullins. (2000). "Perceived risks and choices in entrepreneurs' new venture decisions." Journal of Business Venturing. 15(4): 305-322.

Gardner, M. \& L. Steinberg. (2005). "Peer influence on risk taking, risk preference, and risky decision making in adolescence and adulthood: an experimental study." Developmental psychology. 41(4): 625-635.

Garland, D. (2003). "The Rise of Risk". IN Ericson, R. (ed.) Risk and Morality. Toronto, Canada: University of Toronto Press.

Gottfredson, M. R. \& Hirschi, T. (1990). A General Theory Of Crime. Stanford, USA: Stanford University Press.

Hensley, W. E. (1977). "Probability, personality, age, and risk taking." The Journal of psychology. 95(1): 139-145.

Holt, T. J. \& E. Lampke. (2010). "Exploring Stolen Data Markets Online: Products And Market Forces." Criminal Justice Studies. 23(1), 33-50.

Holt, T. J. \& O. Smirnova \& Y. T. Chua \& H. Copes. (2015). "Examining The Risk Reduction Strategies Of Actors In Online Criminal Markets." Global Crime. 16(2): 81-103.

Horvath, P. \& M. Zuckerman. (1993). "Sensation seeking, risk appraisal, and risky behavior." Personality and individual differences. 14(1): 41-52.

Jacobs, B. A. \& V. Topalli \& R. Wright. (2000). "Managing Retaliation: Drug Robbery and Informal Sanction Threats." Criminology. 38(1): 171-198

Johnson, B. D. \& M. Natarajan. (1995). "Strategies To Avoid Arrest: Crack Sellers' Response To Intensified Policing." American Journal of Police. 14(3/4): 49-69.

Krueger, R. F. \& P. S. Schmutte \& A. Caspi \& T. E. Moffitt \& K. Campbell \& P. A. Silva. (1994). "Personality traits are linked to crime among men and women: evidence from a birth cohort." Journal of abnormal Psychology. 103(2)" 328-338.

Lane, S. D. \& D. R. Cherek. (2000). "Analysis of risk taking in adults with a history of high risk behavior." Drug and alcohol dependence. 60(2): 179-187.

Lane, S. D. \& D. R. Cherek \& C. J. Pietras \& O. V. Tcheremissine. (2004). "Alcohol effects on human risk taking." Psychopharmacology. 172(1): 68-77.

Leontiadis, N. \& T. Moore \& N. Christin. (2013). "Pick your poison: pricing and inventories at unlicensed online pharmacies." Proceedings of the fourteenth ACM conference on Electronic commerce. Philadelphia, USA.

Levchenko, K., Pitsillidis, A., Chachra, N., Enright, B., Félegyházi, M., Grier, C., \& McCoy, D. (2011). "Click trajectories: End-to-end analysis of the spam value chain." IEEE Symposium On Security and Privacy.

Little, M. \& L. Steinberg. (2006). "Psychosocial Correlates of Adolescent Drug Dealing in the Inner City Potential Roles of Opportunity, Conventional Commitments, and Maturity." Journal of Research in Crime and Delinquency. 43(4): 357-386.

Littlejohn, C. \& A. Baldacchino \& F. Schifano \& P. Deluca. (2005). "Internet pharmacies and online prescription drug sales: a cross-sectional study." Drugs: Education, Prevention, and Policy. 12(1): 75-80.

MacCoun, R. \& P. H. Reuter. (1992). "Are the wages of sin $\$ 30$ an hour? Economic aspects of street-level drug dealing." Crime \& Delinquency. 38(4): 477-491.

Martin, J. (2014a). Drugs On The Dark Net: How Cryptomarkets Are Transforming The Global Trade In Illicit Drugs. London, UK: Palgrave Macmillan.

Martin, J. (2014b). "Lost On The Silk Road: Online Drug Distribution And The 'Cryptomarket'." Criminology and Criminal Justice. 14(3): 351-367.

May, T. \& M. Hough. (2004). "Drug markets and distribution systems." Addiction Research \& Theory. 12(6): 549-563. 
McCarthy, B. (2002). "New Economics Of Sociological Criminology." Annual Review of Sociology. 28: 417442.

McCarthy, B. \& J. Hagan. (2001). "When Crime Pays: Capital, Competence, And Criminal Success." Social Forces. 79(3): 1035-1060.

McCarthy, B. \& J. Hagan. (2005). "Danger and the decision to offend." Social Forces. 83(3): 1065-1096.

Moloney, M. \& G. Hunt \& K. Joe-Laidler. (2015). "Drug Sales, Gender, And Risk: Notions Of Risk From The Perspective Of Gang-Involved Young Adults." Substance use \& misuse. 50(6): 721-732.

Mungan, M. C. \& J. Klick. (2014). "Forfeiture of Illegal Gains, Attempts, and Implied Risk Preferences." The Journal of Legal Studies. 43(1): 137-153.

Neumann, J.V. \& O. Morgenstern. (1944). Theory of Games and Economic Behavior. Princeton, USA: Princeton University Press.

O’Shaughnessy, M.V. \& J.S.G. Montaner \& S.A. Strathdee \& M.T. Schechter. (1998). "Deadly public policy." Twelfth World AIDS Conference. Geneva, Switzerland.

Pildes, R. H. \& C. R. Sunstein. (1995). "Reinventing the regulatory state." The University of Chicago Law Review. 62(1): 1-129.

Raudenbush, S. W. \& A. S. Bryk \& R. Congdon. (2004). "HLM 7 for Windows: Scientific Software International, Inc."

Reuter, P. H. (1983). Disorganized Crime: The Economics of the Visible Hand. Cambridge, USA: MIT Press.

Reuter, P. H. \& J. Haaga. (1989). "The organization of high-level drug markets." Online: http://www.rand.org/content/dam/rand/pubs/notes/2006/N2830.pdf.

Reuter, P. H \& M. A. Kleiman. (1986). "Risks and prices: an economic analysis of drug enforcement." Crime and justice. 7: 289-340.

Rhodes, T. (2002). "The 'risk environment': a framework for understanding and reducing drug-related harm." International Journal of Drug Policy. 13: 85.94.

Romer, D. \& A. L. Duckworth \& S. Sznitman \& S. Park. (2010). "Can adolescents learn self-control? Delay of gratification in the development of control over risk taking." Prevention Science. 11(3): 319330.

Scott, M. A. \& J. S. Simonoff \& B. D. Marx. (2013). The Sage Handbook Of Multilevel Modeling. New York, USA: Sage.

Skolnick, J. H. \& T. Correl \& E. Navarro \& R. Rabb. (1989). "The social structure of street drug dealing." Online: https://www.ncjrs.gov/pdffiles1/Digitization/146833NCJRS.pdf.

Smith, R. (2009). "Understanding entrepreneurial behaviour in organized criminals." Journal of Enterprising Communities: People and Places in the Global Economy. 3(3): 256-268.

Sniders, T. \& R. Bosker. (1999). Multilevel analysis. An introduction to basic and advanced multilevel modeling. London, UK: Sage.

Soska, K. \& N. Christin. (2015). "Measuring the longitudinal evolution of the online anonymous marketplace ecosystem."24th USENIX Security Symposium. Washington D.C., USA.

Stafford, M. C. \& M. Warr. (1993). "A reconceptualization of general and specific deterrence." Journal of Research in Crime and Delinquency. 30(2): 123-135.

Swogger, M. T. \& Z. Walsh \& C. W. Lejuez \& D. S. Kosson. (2010). "Psychopathy and risk taking among jailed inmates." Criminal justice and behavior. 37(4): 439-452.

Topalli, V. \& R. Wright \& R. Fornango. (2002). "Drug dealers, robbery and retaliation. Vulnerability, deterrence and the contagion of violence." British Journal of Criminology. 42(2): 337-351.

Tremblay, P. \& M. Bouchard \& S. Petit. (2009). "The Size And Influence Of A Criminal Organization: A Criminal Achievement Perspective." Global Crime. 10(1-2): 24-40.

U.S. Department of Homeland Security. (2014). Non-Intrusive Inspection Systems Program. Online: https://www.dhs.gov/publication/non-intrusive-inspection-systems-program. 
UNODC. (2005). World Drug Report. Online:

https://www.unodc.org/pdf/WDR_2005/volume_1_chap2.pdf.

van Duyne, P. C. (1999). “Mobsters are human too." IN Canter, D. \& L. Alison. (eds). Offender

Profiling Series: Profiling in Policy and Practice, Vol. 2. Burlington, USA: Ashgate Publishing.

Viscusi, W. K. (1986). "Market Incentives For Criminal Behavior." IN R. B. Freeman \& H. J. Holzer (eds.) The Black Youth Employment Crisis. Chicago, USA: University of Chicago Press.

Volery, R. (2015). "Drug Dealing On Cryptomarkets: Shipping Techniques And Knowledge Transfrom [ORIGINAL TITLE IN FRENCH: Vente de drogues sur les cryptomarchés: Techniques d'envoi et transmission des connaissances]." Masters at the École des sciences criminelles, Université de Lausanne.

Weinfurt, K. P. \& P. J. Bush. (1995). "Peer Assessment of Early Adolescents Solicited to Participate in Drug Trafficking: A Longitudinal Analysis." Journal of Applied Social Psychology. 25(24): 21412157.

Werb, D. \& T. Kerr \& K. Li \& J. Montaner \& E. Wood. (2008). "Risks surrounding drug trade involvement among street-involved youth." The American journal of drug and alcohol abuse. 34(6): 810-820.

World Bank. (2013). "GDP Per Capita." Online: http://data.worldbank.org/indicator/NY.GDP.PCAP.CD World Bank. (2015). "Population, total." Online: http://data.worldbank.org/indicator/SP.POP.TOTL. World Justice Project. (2013). "Rule Of Law Index." Online: http://worldjusticeproject.org/rule-of-lawindex.

World Justice Project. (2015). "Who We Are." Online: http://worldjusticeproject.org/who-we-are-0. Yang, Z. \& R. T. Peterson \& L. Huang. (2001). "Taking the pulse of Internet pharmacies." Marketing Health Services. 21(2): 5-10. 


\section{Tables}

Table 1 : Descriptive statistics

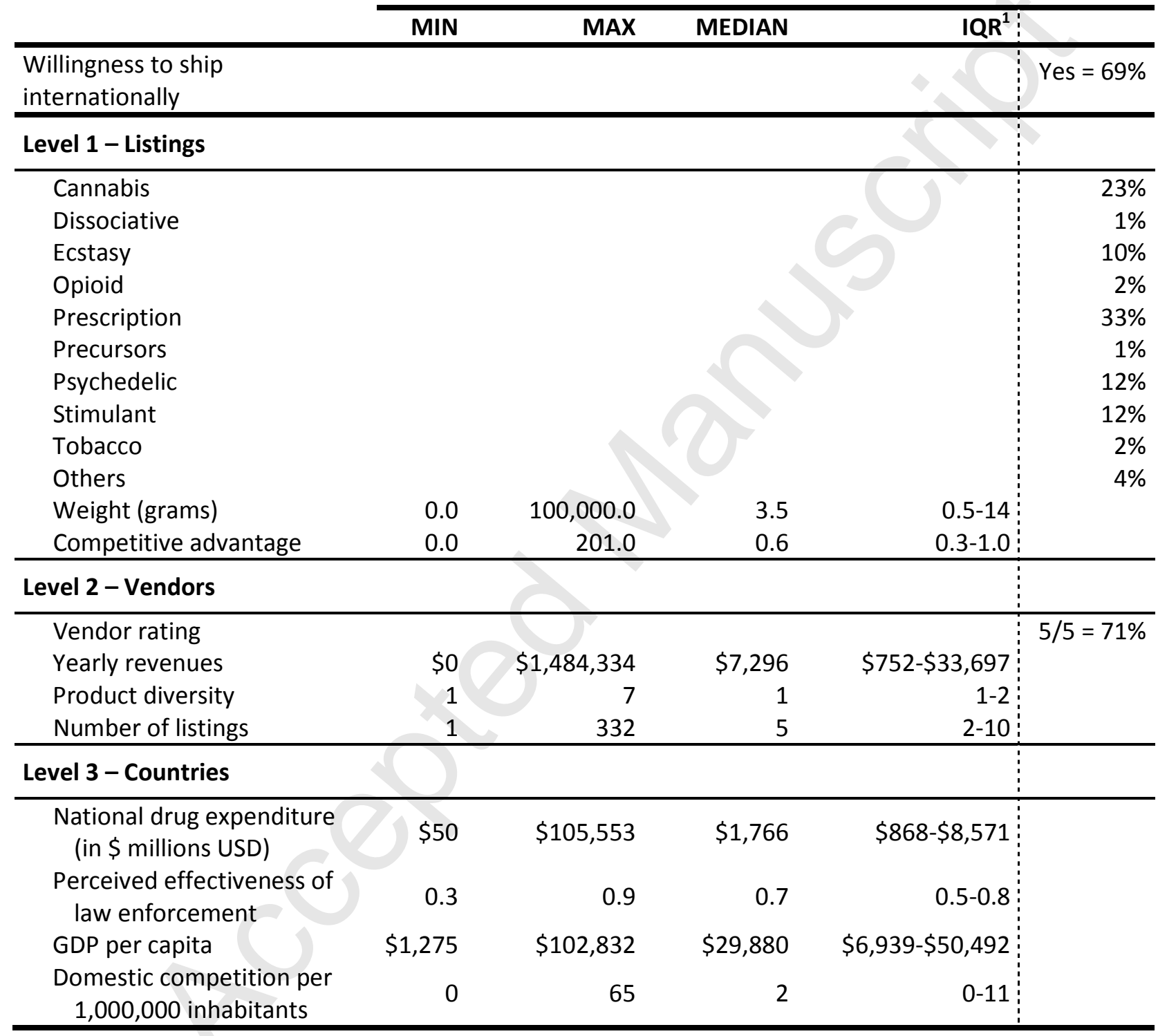

\footnotetext{
${ }^{1}$ IQR stands for interquartile range. Presented here are the first and third quartile.
} 
Table 2: Hierarchical generalized linear model predicting if a listing ships internationally (1) or not (0)*

\begin{tabular}{lrrrr}
\hline Variables & Coefficient & Odds ratio & $\begin{array}{r}95 \% \text { Confidence } \\
\text { interval }\end{array}$ & p-value \\
\hline Level 1 - Listings & & & & \\
$\quad$ Weight (logged) & -0.315 & 0.969 & $0.946-0.993$ & 0.010 \\
$\quad$ Competitive advantage (logged) & -0.024 & 0.975 & $0.939-1.014$ & 0.207 \\
\hline Level 2 - Vendors & & & & \\
$\quad$ Yearly revenues (logged) & -0.020 & 0.980 & $0.934-1.028$ & 0.413 \\
$\quad$ Vendor rating & -0.314 & 0.730 & $0.611-0.873$ & 0.000 \\
$\quad$ Product diversity & -0.011 & 0.989 & $0.927-1.055$ & 0.728 \\
$\quad$ Number of listings & 0.389 & 1.476 & $1.221-1.785$ & 0.000 \\
\hline Level 3 - Environment & & & & \\
$\quad$ National drug expenditure (logged) & -2.115 & 0.121 & $0.052-0.281$ & 0.000 \\
$\quad$ Perceived effectiveness of law enforcement & -16.712 & 0.001 & $0.000-0.009$ & 0.008 \\
$\quad$ GDP per capita (logged) & -3.358 & 0.035 & $0.012-0.102$ & 0.000 \\
$\quad$ Domestic competition per 1,000,000 & -0.029 & 1.029 & $0.756-1.401$ & 0.849 \\
$\quad$ inhabitants (logged) & & & & \\
\hline
\end{tabular}

* Results are with robust standard error estimates and are extracted from the population-average model. The population average model is better suited for the aims of this study because it relates to the overall chance of an event occurring in a population (Nezlek, 2011, p.52). For more information on these specificities, see Raudenbush et al. (2011). 


\section{Appendix A - Sampling method and list of countries}

We collected our data from the first major cryptomarket, SR1, from September $13^{\text {th }}$ to September $15^{\text {th }}$ 2013. The SR1 dataset, once cleaned, included 7,487 listings from 923 vendors operating in 35 countries, down from the initially collected 11,904 listings. 4,417 listings were removed for the following reasons:

- 50 listings were removed because they advertised holding prices. These holding prices were considerably higher than the price for similar listings and including them in our sample would have affected the reliability of our multilevel model.

- 918 listings were removed because they had unknown origins (the "ship from" country) and could not be nested within a country.

- 3,418 listings were removed because they had either no price or no quantity in grams.

- 27 listings were removed because they were nested in 2 countries (Slovakia and Switzerland) that had no indicator for the perceived effectiveness of law enforcement.

- 4 listings were removed because they were nested in 3 countries (United Arab Emirates, Vatican and Saipan) that had too few listings and vendors to be considered in the model.

The final sample provided data on Argentina, Australia, Austria, Belgium, Canada, China, Czech Republic, Denmark, Finland, France, Germany, Ghana, Hong Kong, Hungary, India, Ireland, Italy, Japan, Netherlands, New Zealand, Norway, Pakistan, Peru, Philippines, Poland, Portugal, Singapore, Slovenia, South Africa, Spain, Sweden, Thailand, United Kingdom, United States of America and Vietnam. 